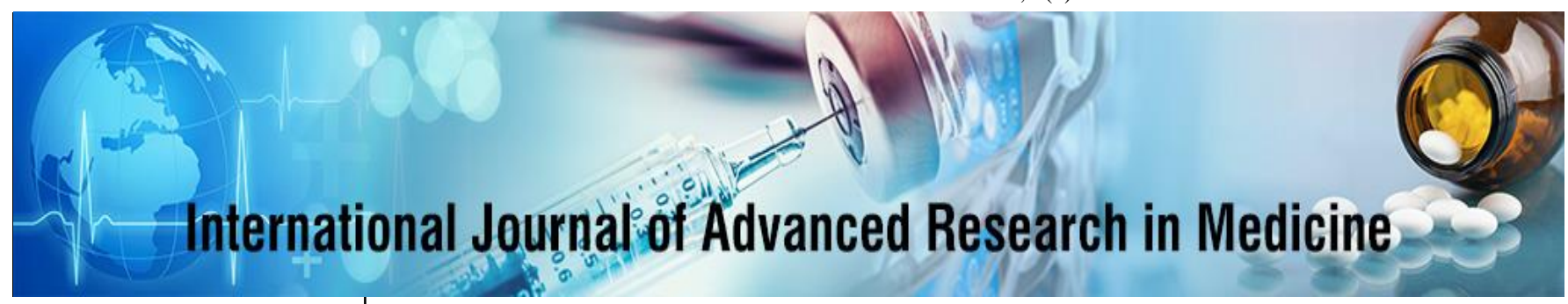

E-ISSN: 2706-9575 P-ISSN: 2706-9567 IJARM 2021; 3(1): 187-191 Received: 03-05-2020 Accepted: 11-06-2020

Dr. Sunil Kumar Gulati MD Medicine, Metro Hospital and Cancer Research Center, Jabalpur, Madhya Pradesh, India

\section{Evaluation of the impact of deranged lipid and glucose profile among stroke patients: An observational study}

\author{
Dr. Sunil Kumar Gulati \\ DOI: https://doi.org/10.22271/27069567.2021.v3.i1d.134
}

\begin{abstract}
Aims: The aim of the study to evaluate the impact of dyslipidemia and hyperglycemia among stroke patients.

Material and Methods: This was a cross-sectional study conducted in the Department of Medicine, Metro Hospital and Cancer Research Centre, Jabalpur, MP, India from October 2018 to January 2020. During the study period, a total of 140 stroke patients were admitted out of them, 120 patients were participated in this cross-sectional study. Age, gender, and social status, past medical history (hypertension, diabetes, atrial fibrillation, ischemic heart disease, transient ischemic attack, and previous history of stroke), other risk factors (smoking, alcohol use, and obesity/BMI) and family history were obtained from all the patients.

Results: The mean age of 65.9 years with $76.67 \%$ of them aged above 50 years, and $66.67 \%$ of them were males. The co-morbidity, $94(78.33 \%)$ patients had hypertension, 65(54.17\%) patients had diabetes mellitus, and $12(10 \%)$ patients had transient ischemic attack. 59 patients $(49.17 \%)$ were smokers, the majority of the smokers were males, and $13(10.83 \%)$ patients were obese with a BMI above $30 \mathrm{~kg} / \mathrm{m} 2$ with a mean of $32.3 \mathrm{~kg} / \mathrm{m} 2.96(80 \%)$ patients had a family history of hypertension, 63 $(52.5 \%)$ patients had a family history of stroke and $73(60.83 \%)$ patients had a family history of diabetes mellitus. Regarding the lipid profile and hyperglycemia, it was found that, 35 patients $(29.17 \%)$ had LDL greater than $130 \mathrm{mg} / \mathrm{dl}, 23$ patients $(19.17 \%)$ had cholesterol equal or greater than $200 \mathrm{mg} / \mathrm{dl}, 20(16.67 \%)$ patients had TAG equal or greater than $200 \mathrm{mg} / \mathrm{dl}, 73(60.83 \%)$ patients had low HDL. 63 patients $(52.5 \%)$ had HbA1C levels equal or greater than $6.5 \%$ and 66 patients $(55 \%)$ had FBG equal or greater than $126 \mathrm{mg} / \mathrm{dl}$. The mean level of cholesterol, LDL, HDL and TAG were 162.7 , $115.4,41.7$, and $134.1 \mathrm{mg} / \mathrm{dl}$ respectively. The mean of the HbAlc was $7.1 \%$, while the mean of FBG was $156 \mathrm{mg} / \mathrm{dl}$.

Conclusion: Most of the patients with stroke had low HDL levels, high levels of FBG and HbA1c. Hypertension, DM, smoking and family history of HTN and DM are significant risk factors for the incidence of stroke.
\end{abstract}

Keywords: Hyperglycemia, lipid profile, HTN, stroke

\section{Introduction}

Stroke is defined as abrupt onset of symptoms and/or sign of focal and global loss of cerebral function lasting for at least $24 \mathrm{hrs}$ with no apparent cause other than of vascular origin [1]. Stroke is diagnosed based on history, clinical findings and the brain imaging. Stroke is classified on the basis of its etiology as either ischemic or hemorrhagic ${ }^{[2]}$. In India, the prevalence of stroke is estimated as 203 per 100,000 above 20 years. In India, stroke incidence is 105 to $152 / 100,000$ persons per year ${ }^{[3]}$. Ischemic stroke accounts for about $85 \%$ of cases, primary intracerebral hemorrhage $(\mathrm{ICH})$ for $10 \%$ and subarachnoid hemorrhage (SAH) for the remaining 5\% ${ }^{[4]}$. The role of lipid and lipoprotein biomarkers, such as of total cholesterol (TC), high-density lipoprotein cholesterol (HDL-C), low-density lipoprotein cholesterol (LDL-C), and triglycerides (TG), in risk prediction of ischemic heart disease is well established 1,2,4 but their value as independent predictors for ischemic stroke is less certain ${ }^{[5]}$. In most epidemiological cohorts, the relationship between lipids and stroke is complex and varies by stroke subtype, with associations strongest for atherosclerotic subtypes. Conversely, there is an increased risk of ICH at low cholesterol levels, and there is evidence that small vessel disease may share a similar profile of inverse association with lipid levels. The associations also depend on the specific lipid component considered, with the data strongest for TC and LDL-C ${ }^{[6]}$.
Dr. Sunil Kumar Gulati MD Medicine, Metro Hospital and Cancer Research Center, Jabalpur, Madhya Pradesh, India 
Hypertension, diabetes, and dyslipidemia are major modifiable risk factors for CVD. The prevalence of these risk factors has increased sustainably in China, and even worse, many middle-aged people have at least two chronic diseases ${ }^{[7-9]}$. The reason for disease clustering is probably mutual risk factors, such as aging, obesity, and smoking. Nevertheless, few analyses focused on common risk factors for hypertension, diabetes, and dyslipidemia. In addition, previous studies have shown that the clustering of two risk factors increases the risk of CVDs ${ }^{[10,11]}$. However, limited evidence is available with regard to the relationship between multiple chronic diseases and CVDs. The severity of acute stroke is associated with the incidence and degree of hyperglycemia and the mortality was significantly increased in hyperglycemic patients ${ }^{[12]}$. Undoubtedly, dyslipidemia and diabetes are two of the common disorders all over the world, and they are considered as risk factors for many diseases, while stroke is a clinical condition that directly and badly affects life and may result in death. Therefore, the aim of this study was to determine the impact of dyslipidemia and hyperglycemia in stroke patients and to assess the risk factors associated with stroke among these patients and this would influence the treatment course and prognosis of stroke per se.

\section{Material and Methods}

This was a cross-sectional study conducted in the Department of Medicine, India from October 2018 to January 2020, after taking the approval of the protocol review committee and institutional ethics committee. After taking informed consent detailed history was taken from the patient or the relatives. The technique, risks, benefits, results and associated complications of the procedure were discussed with all patients.

\section{Methodology}

Total 140 stroke patients with a confirmed diagnosis on CT scan were admitted to the hospital, out of them, 120 patients were participated in this study.

Patients without a confirmed CT scan, those suspected of having a transient ischemic attack or patients, who refused to undergo the interview or give blood sample, were excluded. Age, gender, and social status, past medical history (hypertension, diabetes, atrial fibrillation, ischemic heart disease, transient ischemic attack, and previous history of stroke), other risk factors (smoking, alcohol use, and obesity/BMI) and family history were obtained from all the patients.

Fasting venous blood samples were collected from stroke patients to measure cholesterol, TAG, LDL, HDL, FBG, and HbA1c. Hyperlipidemia was defined as cholesterol equal or more than $200 \mathrm{mg} / \mathrm{dl}$, TAG of equal or more than $200 \mathrm{mg} /$ $\mathrm{dl}$, LDL of equal or more than $130 \mathrm{mg} / \mathrm{dl}$, and HDL of less than $40 \mathrm{mg} / \mathrm{dl}$ in men and less than $50 \mathrm{mg} / \mathrm{dl}$ in women ${ }^{[13]}$. Patients were diagnosed as diabetic if FBG level is equal or more than $126 \mathrm{mg} / \mathrm{dl}$ on more than one occasion or random blood glucose level more than $200 \mathrm{mg} / \mathrm{dl}$ on one occasion with symptoms of hyperglycemia or $\mathrm{HbA1c}$ equal or more than $6.5 \%{ }^{[14]}$. Patients who were normoglycemic at the time of presentation, but with a history of diabetes, taking insulin or oral hypoglycemic were also labelled as diabetics. A smoker was defined as a person who smoked at least one cigarette per day for the preceding 3 months or more, or use tobacco in any form ${ }^{[15]}$. Obesity was defined as a person with a BMI of $30 \mathrm{~kg} / \mathrm{m} 2$ or more.

\section{Results}

Out of them, 120 patients were participated in this crosssectional study, giving a response rate of $85.71 \%$. The patients had a mean age of 65.9 years with $76.67 \%$ of them aged above 50 years, and $66.67 \%$ of them were males. The demographic distribution of age and gender in the study is shown in Table 1. Studying the co-morbidity, 94 (78.33\%) patients had hypertension, $65(54.17 \%)$ patients had diabetes mellitus, and $12(10 \%)$ patients had transient ischemic attack. 59 patients $(49.17 \%)$ were smokers, the majority of the smokers were males, and $13(10.83 \%)$ patients were obese with a BMI above $30 \mathrm{~kg} / \mathrm{m} 2$ with a mean of 32.3 $\mathrm{kg} / \mathrm{m} 2$. The co-morbidities incidence rates are demonstrated in Table 2.

Table 1: Demographic distribution of age and gender

\begin{tabular}{|c|c|c|}
\hline Gender & $\mathbf{1 2 0}$ & $\mathbf{\%}$ \\
\hline Male & 80 & 66.67 \\
\hline Female & 40 & 33.33 \\
\hline Age in years & \multicolumn{2}{|}{} \\
\hline Below 50 & 28 & 23.33 \\
\hline Above 50 & 92 & 76.67 \\
\hline
\end{tabular}

Table 2: Co-morbidities associated with stroke

\begin{tabular}{|c|c|c|}
\hline Co-morbidities & Number of cases & \% \\
\hline HTN & 94 & $78.33 ; 1$ \\
\hline DM & 65 & 54.17 \\
\hline TIA & 12 & 10 \\
\hline Smoker & 59 & 49.17 \\
\hline BMI $>30$ & 13 & 10.83 \\
\hline
\end{tabular}

BMI: body mass index, TIA: transient ischemic attack, DM: diabetes mellitus, HTN: hypertension

Table 3: Distribution Of family history

\begin{tabular}{|c|c|c|}
\hline Familial history & Number of cases & \% \\
\hline HTN & 96 & 80 \\
\hline Stroke & 63 & 52.5 \\
\hline DM & 73 & 60.83 \\
\hline
\end{tabular}

DM: diabetes mellitus, HTN: hypertension.

Table 4: Lipid profile and fasting blood glucose and Glycosylated Hemoglobin levels in stroke patients

\begin{tabular}{|c|c|c|}
\hline Test & Number of cases & \% \\
\hline LDL $\geq 130 \mathrm{mg} / \mathrm{dl}$ & 35 & 29.17 \\
\hline Cholesterol $\geq 200 \mathrm{mg} / \mathrm{dl}$ & 23 & 19.17 \\
\hline Triglyceride $\geq 200 \mathrm{mg} / \mathrm{dl}$ & 20 & 16.67 \\
\hline Low levels of HDL & 73 & 60.83 \\
\hline $\mathrm{Hb}_{\mathrm{Alc}} \geq 6.5 \%$ & 63 & 52.5 \\
\hline $\mathrm{FBG} \geq 126 \mathrm{mg} / \mathrm{dl}$ & 66 & 55 \\
\hline
\end{tabular}

FBG: Fasting blood glucose, $\mathrm{Hb}_{\mathrm{Alc}}$ : glycosylated hemoglobin

Table 3 shows that $96(80 \%)$ patients had a family history of hypertension, 63(52.5\%) patients had a family history of stroke and $73(60.83 \%)$ patients had a family history of diabetes mellitus (Table 3).

Regarding the lipid profile and hyperglycemia, it was found that, 35 patients $(29.17 \%$ ) had LDL greater than $130 \mathrm{mg} / \mathrm{dl}$, 23 patients $(19.17 \%)$ had cholesterol equal or greater than $200 \mathrm{mg} / \mathrm{dl}, 20(16.67 \%)$ patients had TAG equal or greater than $200 \mathrm{mg} / \mathrm{dl}, 73(60.83 \%)$ patients had low HDL (Table 4). 63 patients $(52.5 \%)$ had $\mathrm{Hb}_{\mathrm{Alc}}$ levels equal or greater 
than $6.5 \%$ and 66 patients $(55 \%)$ had $\mathrm{FBG}$ equal or greater than $126 \mathrm{mg} / \mathrm{dl}$

Table 5: Mean and standard deviation of age, BMI, lipids, glycosylated hemoglobin and fasting blood sugar

\begin{tabular}{|c|c|}
\hline Parameter & Mean $( \pm$ SD) \\
\hline Age $($ years $)$ & $65.9( \pm 10.5)$ \\
\hline Obesity $\left(\right.$ BMI) $\left(\mathrm{kg} / \mathrm{m}^{2}\right)$ & $32.3( \pm 2.7)$ \\
\hline Cholesterol $(\mathrm{mg} / \mathrm{dl})$ & $162.7( \pm 42.4)$ \\
\hline LDL $(\mathrm{mg} / \mathrm{dl})$ & $115.4( \pm 32.8)$ \\
\hline HDL $(\mathrm{mg} / \mathrm{dl})$ & $41.7( \pm 16.2)$ \\
\hline Triglyceride $(\mathrm{mg} / \mathrm{dl})$ & $134.1( \pm 59.4)$ \\
\hline HbA1c $(\%)$ & $7.1( \pm 1.4$ \\
\hline FBG $(\mathrm{mg} / \mathrm{dl})$ & $156( \pm 77.4)$ \\
\hline
\end{tabular}

BMI: body mass index, FBG: fasting blood glucose, HbA1c: glycosylated haemoglobin

The mean and standard deviation of the main variables in this study are shown in Table 5. The mean age of the patients was 65.9 years; the main BMI was $32.3 \mathrm{~kg} / \mathrm{m} 2$. The mean level of cholesterol, LDL, HDL and TAG were 162.7, $115.4,41.7$, and $134.1 \mathrm{mg} / \mathrm{dl}$ respectively. The mean of the HbA1c was $7.1 \%$, while the mean of FBG was $156 \mathrm{mg} / \mathrm{dl}$.

\section{Discussion}

Stroke is classically characterized as a neurological deficit attributed to an acute focal injury of the central nervous system by a vascular cause, including cerebral infarction, intracerebral hemorrhage, and subarachnoid hemorrhage, and is a major cause of disability and death worldwide [16]. The presentation of stroke is variable, ranging from subtle to severe, depending on the area of brain involved and the nature of the attack ${ }^{[17]}$. The role of dyslipidemia in the pathogenesis of stroke is less clear. Studies have shown conflicting findings regarding the association between dyslipidemia and stroke ${ }^{[18]}$. In this study, the impact of dyslipidemia, hyperglycemia and other stroke risk factors were studied among stroke patients. the male to female ratio was almost $2: 1$, similar to other studies ${ }^{[19,20]}$. Although a study from Oxford shire, showed that males are more affected than females by genetic factors, the family history are more likely to be found in females than in males. ${ }^{21}$ Regarding the age distribution of stroke patients in the study, the mean age was 65.6 years $( \pm 10.5)$ which is similar to a result of a study in India and a study in Palestine 10 years ago that showed a mean age of 69 years ${ }^{[20,22]}$. The majority, 93(76.67\%) patients, were above the age of 50 years. Again this result is almost similar to the study conducted in Palestinian that found $82 \%$ of patients were above the age of 60 years. ${ }^{22}$ These results indicate that the incidence of stroke is higher for those who are above 50 years old. On the other hand, the mean BMI of stroke patients was $32.3 \mathrm{~kg} / \mathrm{m} 2( \pm 2.7)$ with $13(10.83 \%)$ patients above $30 \mathrm{~kg} / \mathrm{m} 2$ and this is higher than a study carried in Japan ${ }^{[23]}$. Although obesity and higher BMI is established as a risk factor for coronary artery disease, its role as a risk factor for stroke remains controversial. Although there are many possible causes of human disease, family history is often one of the strongest risk factors for common disease complexes such as stroke, cancer, and diabetes. We found that a family history for HTN, stroke, or DM was associated with the increased incidence of stroke. Family history of
HTN (80\%) was found as the main cerebrovascular risk factor in stroke, followed by a family history of DM $(60.83 \%)$ and stroke $(52.5 \%)$.

therefore, family history is thought to be a good predictor of stroke risk because family members most closely represent the unique genomic and environmental interactions that an individual experiences ${ }^{[24]}$. The involvement of hypertension, diabetes, cigarette smoking, and others in the formation of stroke is widely established ${ }^{[25-27]}$. Hypertension $(78.3 \%)$ was found to be the main stroke risk factor, followed by smoking (49.17\%) and diabetes (54.17\%). Moreover, the high incidence of hypertension increases the risk of stroke. Although our understanding of the benefits of treating high blood pressure, diabetes and smoking for the secondary prevention of strokes is evolving, we have identified a significant need for improvement in overcoming these risk factors. Stroke prevention clinics may need to be more actively involved in the management of these modifiable risk factors if we are to significantly impact the risk of recurrent stroke ${ }^{[28]}$. The lipid profile of stroke patients was studied and it was found that there were 23 $(19.17 \%)$ patients with cholesterol level $\geq 200 \mathrm{mg} / \mathrm{dl}$ and the mean total cholesterol was $162.7 \mathrm{mg} / \mathrm{dl}( \pm 42.4)$, in agreement with other results which showed no significant correlation between cholesterol level and the risk of stroke [29]. Other studies showed an increased risk of stroke in patients with higher levels of cholesterol [30,31]. This may indicate that the role of high cholesterol levels as a risk factor for stroke is still unclear. High level of TAG (>200mg/dl) were found in 20 patients $(16.67 \%)$, and the mean TAG level was $134.1 \mathrm{mg} / \mathrm{dl}( \pm 59.4)$. These results are similar to several studies that showed the TAG level ranging from 127 to $154 \mathrm{mg} / \mathrm{dl}$ among stroke patients ${ }^{[32]}$. These observations may indicate that the relationship between elevated TAG levels and the risk of stroke is still lacking, and this is in agreement with previous studies showed that no clear relationship between elevated TAG levels and risk of stroke [33, 32]. The mean LDL level was $115.4 \mathrm{mg} / \mathrm{dl}$ $( \pm 32.8), 35$ patients had LDL above $130 \mathrm{mg} / \mathrm{dl}(29.17 \%)$. Conflicting results are reported in the literature about the relationship between elevated levels of LDL and risk of stroke ${ }^{[34]}$. Among male patients, $40(33.33 \%)$ of them had HDL level less than $40 \mathrm{mg} / \mathrm{dl}$, while, 33(27.5\%) female patients had HDL less than $50 \mathrm{mg} / \mathrm{dl}$, and the mean HDL level for both males and females was $41.7 \mathrm{mg} / \mathrm{dl}( \pm 16.2)$. Several studies showed similar findings and suggested that lower levels of HDL are associated with increased risk of stroke, while high levels of HDL are considered as a slight protective indicator against stroke ${ }^{[35]}$. On the other hand, a study conducted in Hawaii, showed no clear relationship between low levels of HDL and the risk of having stroke ${ }^{[36]}$. the results of $\mathrm{HbA1c}$ showed that 63 patients $(52.5 \%)$ had HbAlc $\geq 6.5 \%$ with a mean of $7.1 \% \quad( \pm 1.4)$. the $\mathrm{FBG} \geq 126 \mathrm{mg} / \mathrm{dl}$ was found in $66(55 \%)$ patients with a mean of $156 \mathrm{mg} / \mathrm{dl}( \pm 77.4)$. the results about HbA1c and FBG were similar to other studies that showed a relationship between hyperglycemia and high $\mathrm{HbA1c}$, and the risk of developing stroke ${ }^{[37-39]}$. In diabetic patients, several mechanisms suggest that the prolonged hyperglycemia leads to stroke. these include vascular endothelial dysfunction, increased early-age arterial stiffness, systemic inflammation and thickening of the capillary basal membrane ${ }^{[40]}$. 


\section{Conclusion}

The concept of aggressive management of dyslipidemia is changing dramatically in the past few years, as results of evidences from recent studies, very low lipid levels are also harmful to health. In developing countries like ours where there is very high prevalence of dyslipidemia because of various reasons like improper dietary habits, unhealthy life style etc. there should be a specific cut off level of lipids for treatment. Most of the patients with stroke had low HDL levels, high levels of FBG and HbA1c. Hypertension, DM, smoking and family history of HTN and DM are significant risk factors for the incidence of stroke. Less patients had high LDL, high cholesterol and high TAG, making the effect of these parameters on the incidence of stroke is still controversial.

\section{Reference}

1. Young AR, Ali C, Duretête A, Vivien D. Neuroprotection and stroke: Time for a compromise. J Neurochem 2007;103(4):1302-9.

2. Argade DS, Shendye DRJ. Study of serum high sensitivity $\mathrm{C}$ - reactive protein and lipid profile in ischemic and hemorrhagic stroke. Int $\mathbf{J}$ Clin Biomed Res 2019;42-5.

3. Kamalakannan S, Gudlavalleti ASV, Gudlavalleti VSM, Goenka S, Kuper H. Incidence \& prevalence of stroke in India: A systematic review. Ind J Med Res. 2017;146(2):175-185.

4. Smith NM, Pathansali R, Bath PMW. Vascular Medicine 1999;25(2):50-5

5. Pikula A, Beiser AS, Wang J, Himali JJ, Kelly- Hayes M, Kase CS et al. Lipid and lipoprotein measurements and the risk of ischemic vascular events: Framingham Study. Neurol 2015;84(5):472-9.

6. Yaghi S, Elkind MSV. Lipids and Cerebrovascular Disease: Research and Practice. Strok 2015;46(11):3322-8.

7. Liu LS. Chinese guidelines for the management of hypertension. Beijing: People's Medical Publishing House (China), 2018.

8. Zhang DD, Tang X, Jin DY. Prevalence of diabetes in Chinese adults: a Meta-analysis. Zhonghua Liu Xing Bing Xue Za Zhi 2018;39:852-7.

9. Joint Committee for Developing Chinese Guidelines on Prevention and Treatment of Dyslipidemia in Adults. Chinese guidelines on prevention and treatment of dyslipidemia in adults. Zhonghua Xin Xue Guan Bing Za Zhi 2016;44:833-53.

10. Bloomgarden ZT. Insulin resistance, dyslipidemia, and cardiovascular disease. Diabetes Care 2007;30:2164-70.

11. Sehestedt T, Hansen TW, Li Y. Are blood pressure and diabetes additive or synergistic risk factors? Outcome in 8494 subjects randomly recruited from 10 populations. Hypertens Res 2011;34:714-21

12. Melamed E, Reactive hyperglycaemia in patients with acute stroke, J Neurol Sci 1976;29(2-4):267-275.

13. Fletcher B, Berra K, Ades P. Managing abnormal blood lipids, Circulation 2005;112(20):3184-3209.

14. Marathe PH, Gao HX, Close KL. American diabetes association standards of medical care in diabetes 2017, J Diabetes 2017;9(4):320-324.

15. You R, McNeil JJ, O'Malley HM, Davis SM, Donnan GA. Risk factors for lacunar infarction syndromes, Neurology 1995;45(8):1483-1487.
16. Sacco RL, Kasner SE, Broderick JP. An updated definition of stroke for the 21st century," Stroke 2013;44(7):2064-2089.

17. Victor M, Ropper AH, Adams RD. Adams and Victor's principles of neurology, McGraw Hill, New York, USA, 2001.

18. Goldstein LB. the complex relationship between cholesterol and brain hemorrhage, Circulation 2009;119(16):2131-2133.

19. Qari FA. Profile of stroke in a teaching university hospital in the western region, Saudi Medical Journal 2000;21(11):1030-1033.

20. Marwat MA, Usman M, Hussain M. Stroke and its relationship to risk factors, Gomal Journal of Medical Sciences 2009;7(1):17-21.

21. Touze E, Rothwell PM. Sex differences in heritability of ischemic stroke: a systematic review and metaanalysis, Stroke 2008;39(1):16-23.

22. Sweileh WM, Sawalha AF, Al-Aqad SM, Zyoud SH, Al-Jabi SW. epidemiology of stroke in Northern Palestine: a 1-year, hospital-based study, Journal of Stroke and Cerebrovascular Diseases 2008;17(6):406411.

23. Kawase S, Kowa H, Suto Y. Association between body mass index and outcome in Japanese ischemic stroke patients, Geriatrics \& Gerontology International 2017;17(3):369-374.

24. Kardia SL, Modell SM, Peyser PA. Family-centered approaches to understanding and preventing coronary heart disease, American Journal of Preventive Medicine 2003;24(2):143-151.

25. Gilmore RM, Stead LG. The role of hyperglycemia in acute ischemic stroke, Neurocrit Care 2006;5(2):153158.

26. Arboix A, Martí-Vilalta JL. New concepts in lacunar stroke etiology: the constellation of small-vessel arterial disease, Cerebrovascular Diseases 2003;17(1):58-62.

27. Lou H, Dong Z, Zhang P. Joint effect of smoking and diabetes on stroke, Zhonghua Liu Xing Bing Xue Za Zhi 2017;38(9):1274-1277.

28. Mouradian MS, Majumdar SR, Senthilselvan A, Khan K, Shuaib A. How well are hypertension, hyperlipidemia, diabetes, and smoking managed after a stroke or transient ischemic attack? Stroke 2002;33(6):1656-1659.

29. Castilla-Guerra L, Fernández-Moreno MDC, ÁlvarezSuero J. Secondary stroke prevention in the elderly: New evidence in hypertension and hyperlipidemia," European Journal of Internal Medicine 2009;20(6):586590.

30. Zhang X, Patel A, Horibe H. Cholesterol, coronary heart disease, and stroke in the Asia Pacific region, International Journal of Epidemiology 2003;32(4):563572.

31. Lindenstrom E, Boysen G, Nyboe J. Influence of total cholesterol, high density lipoprotein cholesterol, and triglycerides on risk of cerebrovascular disease: the Copenhagen city heart study, BMJ 1994;309(6946):1115.

32. Goff DC, A. Bertoni AG, Kramer H. Dyslipidemia prevalence, treatment, and control in the multi-ethnic study of atherosclerosis (MESA): gender, ethnicity, and coronary artery calcium, Circulation 2006;113(5):647656. 
33. Tziomalos K, Athryros VG, Karagiannis A, Mikhalidis DP. Dyslipidemia as a risk factor for ischemic stroke, Current Topics in Medicinal Chemistry 2009;9(14):1291-1297.

34. Zhang Y, Tuomilehto J, Jousilahti P, Wang Y, Antikainen R, Hu G. Total and high-density lipoprotein cholesterol and stroke risk, Stroke 2012;43(7):17681774.

35. Basharat Z, Mumtaz S, Rashid F. Prevalence of risk factors of ischemic stroke in a local Pakistani population. Highdensity lipoproteins, an emerging risk factor, Neurosciences (Riyadh) 2012;17(4):357-362.

36. Iemolo F, Beghi E, Cavestro C, Micheli A, Giordano A, Caggia E. Incidence, risk factors and short-term mortality of stroke in Vittoria, southern Italy, Neurological Sciences 2002;23(1):15-21.

37. Wei JW, Heeley EL, Wang JW. Comparison of recovery patterns and prognostic indicators for ischemic and hemorrhagic stroke in China, Stroke 2010;41(9):1877-1883.

38. Capes SE, D Hunt D, Malmberg K, Pathak P, Gerstein HC. Stress hyperglycemia and prognosis of stroke in nondiabetic and diabetic patients, Stroke 2001;32(10):2426-2432.

39. Curb JD, Abbott RD, Rodriguez BL. High density lipoprotein cholesterol and the risk of stroke in elderly men: the Honolulu heart program, American Journal of Epidemiology 2004;160(2):150-157.

40. Chen R, Ovbiagele B. Feng W, Diabetes and stroke: epidemiology, pathophysiology, pharmaceuticals and outcomes American, Journal of Medical Sciences 2016;351(4):380- 386 . 